\title{
疲労き裂伝ぱ速度に対する複合変動モデルの検討
}

\section{市川昌弘* 秋田敏*}

\author{
Examination of Composite Variability Model for Fatigue \\ Crack Propagation Rate \\ by \\ Masahiro ICHIKAwA* and Satoshi Akita*
}

In this paper, the composite variability model as a stochastic model of the fatigue crack propagation rate has been examined, and compared with the intra-specimen variability model examined in the previous papers. The composite variability model assumes that the parameter $C$ in the Paris's law $d a / d N=C(\Delta K)^{m}$ is a random variable of which randomness is composed of the variability within a specimen and that between specimens, whereas the intra-specimen variability model assumes only the former component. First, equations for the mean value, $\mu_{N}$, and the coefficient of variation, $\eta_{N}$, of the crack propagation life $N$ were derived based on the composite variability model. These equations were found to be in good agreement with our experimental results. With respect to $\eta_{N}$, the composite variability model was in better agreement with the experimental results than the intraspecimen variability model was. The correlation distance estimated by the composite variability model was of the same order as that estimated by the intra-specimen variability model, although the former is a little smaller than the latter. It was also shown that the scatters of $C_{S}$ and $m_{s}$ observed experimentally when the equation $d a / d N=C_{s}(\Delta K)^{m} s$ is applied to each specimen could be explained by the composite variability model as well as by the intra-specimen variability model. As a whole, the composite variability model was found to be in a slightly better agreement with our experiment than the intra-specimen variability model was, but more experimental examinations are necessary before reaching a definite conclusion. キー・ワード : 疲労き裂伝ぱ速度, 統計破壞力学, 複合変動モデル

\section{1 緒言}

疲労に対する機械構造物の信頼性評価を高精度化す るためには，疲労き裂伝ぱ速度 $d a / d N$ の確率特性を 明らかにし，これを信頼性解析にとり入れることが必 要である. 同一材料の多数の試験片について，応力幅 $\Delta \sigma=$ 一定の条件下で $d a / d N$ を測定し, 試験片ごとに Paris 則 $d a / d N=C(\Delta K)^{m}$ をあてはめると, $C$ と $m$ の值は試験片によって異なり, $\log C$ と西はいずれる 正規分布に注淩従い，から $\log C$ と的の間には強い萯 の相関があることが実験により明らかにされている。

したがって, $d a / d N$ の最も単純な確率モデルとして は，Cとmを試験片によって異なった值をとる確率変 数とみなすモデルが考光られる。これを試験片間変動 モデルとよぶことにする．これに対し，Cを試験片内 で空間的に変動する確率変数とみなし，mは一定值と するモデルが考光られている. これを試験片内変動モ デルとよぶことにする．著者らは前報で，上述のよう な実験的に観察される $C, m$ の試験片間でのばらつき が，試験片内変動モデルルよってもほぼ説明されるこ
とを示した、また，き裂伝ば寿命の確率特性もこのモ

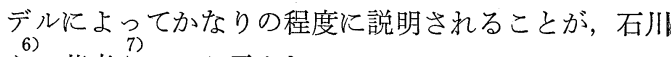
ら，著者らにより示されている.

ところで, 試験片内変動モデルには相関距離 (Cの 相関が無視できないと考光られる空間距離) といらパ ラメータがふくまれているが，著者らの実験データに ついて相関距離を推定したところ, 結晶粒径より約 1 けた大きな值が得られた。.これより，相関距離と材料 組織との関係についての研究の必要性を指摘すると共 に, Cの変動として試験片内での空間的変動々試験片 間での変動の双方を同時に考慮したモデルの可能性を 示唆した．以下このモデルを複合変動モデルとよぶこ とにする。このモデルは, 疲労寿命のばらつきに関し て以前田中らによって提唱された類似の考方方と軌を 一にするものである.

以上の経過をふま方，疲労き裂伝ぱ速度の確率特性 に関する研究の一環として，本論文では複合変動モデ ルに対して数学的解析を行い, 解析結果を著者らの実 験と対比してこのモデルに検討をくわえ, 前報で検討

†本報を「波労き裂伝ぱ速度の信頼性工学的研究 (第 4 報)」(Reliability Engineering Approach to Fatigue Crack Propagation Rate, IV) とする.

原稿受理 昭和61年 2 月22日 Received Feb. 22, 1986

* 正会員電気通信大学 調布市調布ヶ丘, University of Electro-Communications, Chofugaoka, Chofu 
した試験片内変動モデルとの比較を行った.

\section{2 き裂伝ぱ寿命の解析ならびに実験との対比}

\section{$2 \cdot 1$ 理論解析}

複合変動モデルにもとづいて, き裂伝ぱ寿命の解析 を行う。き裂伝ぱ経路上の各点で, 次式が成立するも のとする.

$$
\frac{d a}{d N}=C(\Delta K)^{m}
$$

また, Cの変動は試験片内変動之試験片間変動の二つ の成分から構成されて叔り,

$$
C=C^{*} g l
$$

すなわち

$$
\log C=\log C^{*}+\log g+\log l
$$

なる構造を有するものとする。ここで $C^{*}$ は定数で, gとlはそれぞれ試験片内変動々試験片間変動を表す 確率変数である.さらに，gとlはいずれも対数正規 分布に従うものとする. ただし， $g, l$ の対数平均值 は 0 とする。すなわち

$$
\begin{aligned}
& \mu(\log g)=0 \\
& \mu(\log l)=0
\end{aligned}
$$

したがって, $\log C$ は試験片内では $\log C^{*}+\log g$ な る值のまわりに正規分布しており， $\log C^{*}+\log g$ 自身 は $\log C^{*}$ のまわりに正規分布している.

以上のモデルにしたがって，き裂がある長さ $a_{1}$ か らある長さ $a_{2}$ まで伝ぱするのに要する繰返し数 $N を$ 求める．前報に打ける試験片内変動モデルと同様に, $C$ は試験片内では長さ $\delta$ の区間を単位として変動する ものとする (Fig. 1). 実際にはC は伝ば経路に沿って,

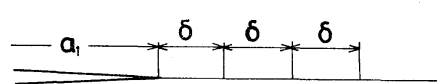

Fig. 1. Variation of $C$ within a specimen.

相関を有しながら連続的に変化すると考えられるが, Fig. 1 はこのような変動の本質を抽出したものとみる ことがでさる。すなわち， $＼rightarrow 0$ のとき相関は0（す なわち任意の 2 点の $C$ は互いに独立), $\delta \rightarrow \infty$ とき相 関は1（すなわちCは場所によらず一定）となる。 を相関距離とよぶことにする。なお。式(1)の（は確定 值とする.

著者らの実験結果と比較するため, Fig. 2 のような 中央き裂試験片に和いて，応力幅 $\Delta \sigma=$ 一定の条件下 でき裂が伝ぱする場合を考学る。初期長さ $a=a_{1}$ から ある長さ $a_{2}$ までの間に，長さ $\delta$ の区間が $n$ 個あると する. $i$ 番目の区間 $a_{1}+(i-1) \delta<a<a_{1}+i \delta$ に和忷 るCの值を $C^{*} g l_{i}$ とし，この区間をき裂が通過するの に要する繰返し数を $N_{i}$ とすると, 式(1)より

$$
N_{i}=\frac{1}{C^{*}(\Delta \sigma \sqrt{\pi})^{m}} \frac{1}{g l_{i}} \int_{a_{1+(i-1) \delta}}^{a_{1}+i \delta}\left(a \sec \frac{\pi a}{W}\right)^{-m / 2} d a
$$

\section{$\Delta \sigma=$ const}

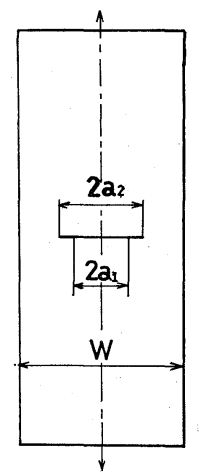

Fig. 2. Center cracked specimen.

ただし，中央き裂試験片の $\Delta K$ として次式を用いた。

$$
\Delta K=\Delta \sigma \sqrt{\pi a \sec (\pi a / W)}
$$

$a=a_{1}$ から $a=a_{2}$ までのき裂伝ぱ寿命 $N$ は，式(6)より 次式で表される.

$$
N=\frac{1}{C^{*}(\Delta \sigma \sqrt{\pi})^{m}} \frac{1}{g} \sum_{i=1}^{n} \frac{I_{i}}{l_{i}}
$$

ここで

$$
I_{i}=\int_{a_{1+(i-1) \delta}}^{a_{1}+i \delta}\left(a \sec \frac{\pi a}{W}\right)^{-m / 2} d a
$$

式(8)より, $N$ の平均值 $\mu_{N}$ は

$$
\mu_{N}=\frac{1}{C^{*}(\Delta \sigma \sqrt{\pi})^{m}} \mu\left(\frac{1}{g}\right) \mu\left(\frac{1}{l}\right) \sum_{i=1}^{n} I_{i}
$$

ここでル(・) は平均值を表すところで，仮定により $g, l$ は対数正規分布に従らから, 次式がなりたつ.

$$
\begin{aligned}
& \mu\left(\frac{1}{g}\right)=\frac{1+\eta_{g}^{2}}{\mu_{g}} \\
& \mu\left(\frac{1}{l}\right)=\frac{1+\eta_{l}^{2}}{\mu_{l}}
\end{aligned}
$$

ここで, $\left(\mu_{g}, \eta_{g}\right),\left(\mu_{l}, \eta_{l}\right)$ は $g, l$ の (平均值, 変動係数）を表す. 式(10)〜(12)より

$\mu_{N}=$

$$
\frac{1}{C^{*}(\Delta \sigma \sqrt{\pi})^{m}} \frac{1+\eta_{g}^{2}}{\mu_{g}} \frac{1+\eta_{l}^{2}}{\mu_{l}} \int_{a_{1}}^{a_{2}}\left(a \sec \frac{\pi a}{W}\right)^{-m / 2} d a
$$

つぎに $N$ の分散 $\sigma_{N}^{2}$ を求める. 式(8)より

$$
\begin{aligned}
\sigma_{N}^{2}= & \left(\frac{1}{C^{*}(\Delta \sigma \sqrt{\pi})^{m}}\right)^{2}\left[\sigma^{2}\left(\frac{1}{g}\right) \sigma^{2}\left(\sum_{i=1}^{n} \frac{I_{i}}{l_{i}}\right)\right. \\
& \left.+\left\{\mu\left(\frac{1}{g}\right)\right\}^{2} \sigma^{2}\left(\sum_{i=1}^{n} \frac{I_{i}}{l_{i}}\right)+\left\{\mu\left(\sum_{i=1}^{n} \frac{I_{i}}{l_{i}}\right)\right\}^{2} \sigma^{2}\left(\frac{1}{g}\right)\right]
\end{aligned}
$$

となる・ここで $\sigma^{2}(\cdot)$ は分散を表す.ところで

$$
\begin{aligned}
\sigma^{2}\left(\sum_{i=1}^{n} \frac{I_{i}}{l_{i}}\right) & =\sigma^{2}\left(\frac{1}{l}\right) \sum_{i=1}^{n} I_{i}{ }^{2} \\
& \simeq \sigma^{2}\left(\frac{1}{l}\right) \delta \int_{a_{1}}^{a_{2}}\left(a \sec \frac{\pi a}{W}\right)^{-m} d a
\end{aligned}
$$

*1 二つの確率変数 $X, Y$ が互いに独立のとき, 積 $X Y$ の分散は $\sigma_{X} Y^{2}=\sigma_{X}{ }^{2} \sigma_{Y}{ }^{2}+\mu_{X}{ }^{2} \sigma_{Y}{ }^{2}+\mu_{Y}{ }^{2} \sigma_{X}{ }^{2}$ となることを用いた。 
がなりたつ. また $g, l$ は対数正規分布に従うから

$$
\begin{aligned}
& \sigma^{2}\left(\frac{1}{g}\right)=\left(\frac{1+\eta_{g}{ }^{2}}{\mu_{g}}\right)^{2} \eta_{g}{ }^{2} \\
& \sigma^{2}\left(\frac{1}{l}\right)=\left(\frac{1+\eta_{l}{ }^{2}}{\mu_{l}}\right)^{2} \eta_{l}{ }^{2}
\end{aligned}
$$

がなりたつ. 式(14) 〜(17)より

$$
\begin{aligned}
\sigma_{N}^{2} \simeq & \left(\frac{1}{C^{*}(\Delta \sigma \sqrt{\pi})^{m}}\right)^{2}\left(\frac{\left(1+\eta_{g}{ }^{2}\right)\left(1+\eta_{l}{ }^{2}\right)}{\mu_{g} \mu_{l}}\right)^{2} \\
& \times\left[\eta_{l}{ }^{2}\left(1+\eta_{g}{ }^{2}\right) \delta \int_{a_{1}}^{a_{2}}\left(a \sec \frac{\pi a}{W}\right)^{-m} d a\right. \\
& \left.+\eta_{g}{ }^{2}\left\{\int_{a_{1}}^{a_{2}}\left(a \sec \frac{\pi a}{W}\right)^{-m / 2} d a\right\}^{2}\right]
\end{aligned}
$$

ところで, 変数Xが対数正規分布に従らとき, $\mu(\ln X)$ $=\ln \left(\mu_{X} / \sqrt{1+\eta_{X}{ }^{2}}\right)$ がなりたつ. これと式(4)，(5)より 次式が得られる。

$$
\begin{aligned}
& \mu_{g}=\sqrt{1+\eta_{g}^{2}} \\
& \mu_{l}=\sqrt{1+\eta_{l}^{2}}
\end{aligned}
$$

式(19)，(20)を式(13)，(18)に代入すると

$$
\mu_{N}=\frac{\sqrt{\left(1+\eta_{g}^{2}\right)\left(1+\eta_{l}^{2}\right)}}{C^{*}(\Delta \sigma \sqrt{\pi})^{m}} \int_{a_{1}}^{a_{2}}\left(a \sec \frac{\pi a}{W}\right)^{-m / 2} d a
$$

$$
\begin{aligned}
\sigma_{N}{ }^{2} \simeq & \left(\frac{1}{C^{*}(\Delta \sigma \sqrt{\pi})^{m}}\right)^{2}\left(1+\eta_{g}{ }^{2}\right)\left(1+\eta_{l}{ }^{2}\right) \\
& \times\left[\eta_{l}^{2}\left(1+\eta_{g}{ }^{2}\right) \delta \int_{a_{1}}^{a_{2}}\left(a \sec \frac{\pi a}{W}\right)^{-m} d a\right. \\
& \left.+\eta_{g}{ }^{2}\left\{\int_{a_{1}}^{a_{2}}\left(a \sec \frac{\pi a}{W}\right)^{-m / 2} d a\right\}^{2}\right]
\end{aligned}
$$

式(22)，(23)より $N$ の変動係数 $\eta_{N}$ は

$$
\left.\eta_{N} \simeq \eta_{g}{ }^{2}+\delta \eta_{l}{ }^{2}\left(1+\eta_{g}{ }^{2}\right) \frac{\int_{a_{1}}^{a_{2}}\left(a \sec \frac{\pi a}{W}\right)^{-m} d a}{\left\{\int_{a_{1}}^{a_{2}}\left(a \sec \frac{\pi a}{W}\right)^{-m / 2} d a\right\}^{2}}\right\}^{1 / 2}
$$

式(22)〜(24)にて $\eta_{g}=0$ と和くと, 前報で試験片内変動モ デルに対して導いた式と一致する。

なお， $g$ と $l$ の分布形を特定しない場合には，一次 近似法を用いて $\mu_{N}, \sigma_{N}{ }^{2}, \eta_{N}$ の式を導くことができ る.これによれば， $\mu_{N}, \sigma_{N}{ }^{2}, \eta_{N}$ は式(22)，(23)，(24)に

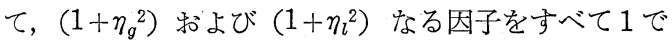
扣さか党た式で与壳られる。

\section{$2 \cdot 2$ 実験との対比}

前節で導いた $\mu_{N}$ と $\eta_{N}$ の理論式を著者らの実験 結果と比較してみる。この実験は 2024-T3 アルミニ ウム合金の中央き裂試験片（板厚 $1 \mathrm{~mm}$, 板幅 $70 \mathrm{~mm}$, 切久き半長 $7 \mathrm{~mm}$ ) 30 個について，応力幅 $\Delta \sigma=59.4$ $\mathrm{MPa}$, 応力比 $R=0.2$ の片振引張応力下で $d a / d N$ を 測定し,き裂半長 $9 \sim 23 \mathrm{~mm}$ の範囲のデータを解析し たものである．本論文でも同じ範囲のデータを対象と する.なお， 3 章で理論的に示すように， $d a / d N=C_{s}$ $(\Delta K)^{m} s$ の形の式を試験片ごとにあてはめたとき， $m_{s}$
と $\log C_{s}$ の期待值はそれぞれ的と $\log C^{*}$ に一致する ので, 以下に和ける理論值の算出では $m, \log C^{*}$ の 值としてはそれぞれ実験で得られた $m_{s}$ の標本平均值 $(=2.939)$ と $\log C_{s}$ の標本平均値 $(=-7.156)$ を用 いる.

まず， $\eta_{N}$ について理論值と実験值を比較する， $a_{1}$ $=9 \mathrm{~mm}$ とし, 式(24)による理論值と実験值との差の平 方和が最小となるように， $\eta_{g}$ と $\eta_{l} \sqrt{\delta / a_{1}}$ の值を決定 すると， $\eta_{g}=0.103, \eta_{l} \sqrt{\delta / a_{1}}=0.0534$ が得られる. これらの数值を用いた場合の理論值と実験值の比較を Fig. 3 に実線で示す．きわめてょい一致がみられる. な怙，破線については 4 章で述べる.

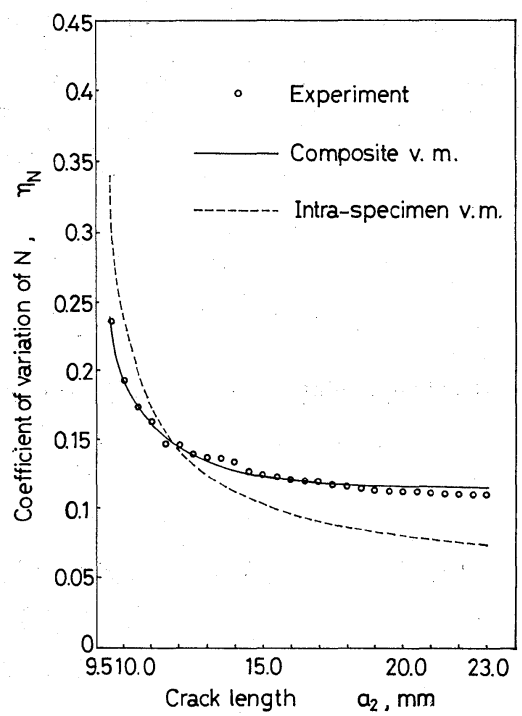

Fig. 3. $\eta_{N}$ predicted by the composite and the intra-specimen variability models (v. m. : variability model).

つぎに， $\mu_{N}$ について理論值と実験值を比較する. 式(22)を次のように書きかえる。

$$
\mu_{N}=\frac{a_{2}-a_{1}}{(\Delta \sigma \sqrt{\pi W} \cdot G(m))^{m}} \cdot \frac{\sqrt{\left(1+\eta_{g}^{2}\right)\left(1+\eta_{l}^{2}\right)}}{10^{\log C^{*}}}
$$

ここで

$$
\begin{aligned}
G(m) & =\left[\frac{1}{\xi_{2}-\xi_{1}} \int_{\xi_{1}}^{\xi_{2}}\{\xi \sec (\pi \xi)\}^{-m / 2} d \xi\right]^{-1 / m} \\
\xi_{1} & =a_{1} / W, \quad \xi_{2}=a_{2} / W
\end{aligned}
$$

式(25)に $a_{1}=9 \mathrm{~mm}, a_{2}=23 \mathrm{~mm}, W=70 \mathrm{~mm}, \Delta \sigma=59.4$ MPa $, \quad m=2.939, \quad \log C^{*}=-7.156, \quad G(2.939)=$ 0.5152 を代入し，さらに上記の $\eta_{g}=0.103, \eta_{l} \sqrt{\delta / a_{1}}$ $=0.0534$ を代入すると， $\mu_{N}=80200 \sqrt{1+(25.7 / \delta)}$ が 得られる(この式の $\delta$ の単位は $\mu \mathrm{m})$. この式による $\mu_{N}$ と $\delta$ の関係を Fig. 4 亿実線で示す. $\mu_{N}$ の実験值 は約 $8 \times 10^{4}$ 回であるから， $\delta$ を拈打よ乞 $400 \mu \mathrm{m}$ 程 度以上とすれば理論值と実験值は汴ぼ一致する。なお 


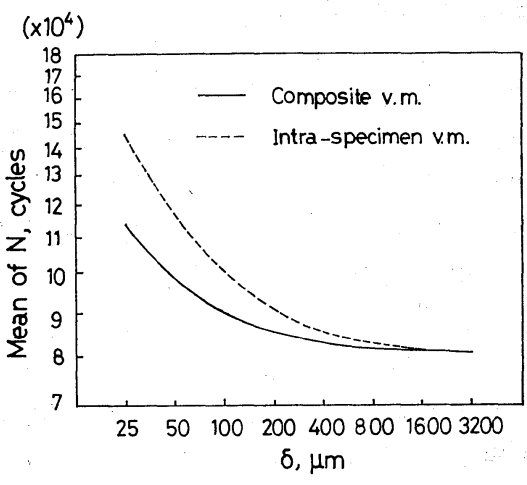

Fig. 4. $\mu_{N}$ predicted by the composite and the intra-specimen variability models (v. m.: variability model).

破線については 4 章で述べる.

$3 \boldsymbol{C}_{s}, \boldsymbol{m}_{s}$ の試験片間変動の解析ならびに 実験との対比

\section{$3 \cdot 1$ 理論解析}

複合変動モデルに従ってき裂が伝ぱするとき， $d a /$ $d N$ の測定值を $\Delta K$ に対して両対数座標上にプロット し，試験片ごとに最小二乗法により直線をあてはめて 次式を得たとする。

$$
\frac{d a}{d N}=C_{s}(\Delta K)^{m} s
$$

このとき $C_{s}$ と $m_{s}$ は試験片ごとに異なる值を示す。 以下では $C_{s}$ と $m_{s}$ の試験片間変動が複合変動モデル によればどのようになるかをしらべる。なお，式(27は 試験片ごとに Paris 則をあてはめたものであり，一方 式(1)は空間の各点に Paris 則をあてはめたものであっ $\tau, C_{s}$ と $C, m_{s}$ とmは互いに異なるものである. 式(1)に式(2)を代入して対数をとると

$$
\log \frac{d a}{d N}=\log C^{*}+\log g+\log l+m \log \Delta K
$$

いま

$$
x=\log \Delta K, \quad y=\log (d a / d N)
$$

ならびに

$$
\alpha=\log C^{*}+\log g, \quad \beta=m, \quad v=\log l
$$

と扮くと，式(28)は次のように書きかえられる。

$$
y=\alpha+\beta x+v
$$

$d a / d N$ を測定し，長さ $\delta$ の区間ごとに測定值を 1 個 ずつ得たとする． $x-y$ 座標上にプロットしたデータ 点を $\left(x_{i}, y_{i}\right)$ とすると, 式(31)より

$$
y_{i}=\alpha+\beta x_{i}+v_{i}
$$

$v_{i}$ は $v(=\log l)$ の実現值である. $\alpha\left(=\log C^{*}+\log g\right)$ の值は試験片によって異なるが，試験片を特定すれば 確定值である. 最小二乗当により試験片ごとに直線を あてはめ，その直線の式を

$$
y=\hat{\alpha}+\hat{\beta} x
$$

とする。式(33)を $d a / d N$ と $\Delta K$ の関係にもどしたのが 式(27)にほかならないから

$$
\hat{\alpha}=\log C_{s}, \hat{\beta}=m_{s}
$$

の関係がある.

さて, 最小二乗法の理論によれば, $\hat{\alpha} と \alpha, \hat{\beta}$ と $\beta$ の間には次式が成立する.

$$
\begin{gathered}
\hat{\alpha}=\alpha+\bar{v}-\bar{x} \frac{\sum\left(x_{i}-\bar{x}\right) v_{i}}{\sum\left(x_{i}-\bar{x}\right)^{2}} \\
\hat{\beta}=\frac{\sum\left(x_{i}-\bar{x}\right)\left[\beta\left(x_{i}-\bar{x}\right)+v_{i}-\bar{v}\right]}{\sum\left(x_{i}-\bar{x}\right)^{2}}
\end{gathered}
$$

また， $\hat{\alpha} と \hat{\beta}$ の間には次式が成立する.

$$
\hat{\alpha}=\bar{y}-\hat{\beta} \bar{x}
$$

ここで $\bar{x}=\sum x_{i} / n, \quad \bar{y}=\sum y_{i} / n, \quad \bar{v}=\sum v_{i} / n$ である. 仮定により $v(=\log l)$ は正規分布に従うから，式(35) の右辺の第 2 項以下の部分は正規分布に従う。また， $\alpha\left(=\log C^{*}+\log g\right)$ も仮定により第 2 項目以下とは独 立な正規分布に従う。したがって, $\hat{\alpha}\left(=\log C_{s}\right)$ は正 規分布に従うことになる。 また式(36)より， $\hat{\beta}\left(=m_{s}\right)$ も 正規分布に従らことになる.

つぎに，式(35)，(36)より $\hat{\alpha}\left(=\log C_{s}\right)$ の期待值は $\alpha$ の 期待值 $\left(=\log C^{*}\right)$ 飞一致し, $\hat{\beta}\left(=m_{s}\right)$ の期待値は $\beta$

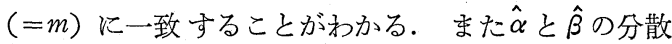
は次式で表される。

$$
\begin{aligned}
\sigma^{2}(\hat{\alpha})= & \sigma^{2}\left(\log C_{s}\right)=\sigma^{2}(\log g) \\
& +\left[\frac{1}{n}+\frac{\bar{x}^{2}}{\sum\left(x_{i}-\bar{x}\right)^{2}}\right] \sigma^{2}(\log l) \\
& \sigma^{2}(\hat{\beta})=\sigma^{2}\left(m_{s}\right)=\frac{\sigma^{2}(\log l)}{\sum\left(x_{i}-\bar{x}\right)^{2}}
\end{aligned}
$$

\section{$3 \cdot 2$ 実験との対比}

実験によれば，式(27)を試験片ごとにあてはめた場合， $\log C_{s}$ と $m_{s_{s}}$ はいずれる正規分布に㴗涪従らことが知 られている. $3 \cdot 2$ 節で示した複合変動モデルによる 理論的予測はこの実験特性と一致している。るた，実 験によれば $\log C_{s}$ と $m_{s}$ の間には強い負の相関が存 在するが， $3 \cdot 2$ 節で得られた式(ろ)の関保はこの実験 特性と一致している.

つぎに，式(38)，(39)により $\log C_{s}$ と $m_{s}$ の分散の值 を計算し，実験值と比較する，2 章の結果にもとづき $\delta=400 \mu \mathrm{m}$ とする. これと $\eta_{l} \sqrt{\delta / a_{1}}=0.0534$ の関係 より， $\eta_{l}=0.253$ となる. また $\eta_{g}=0.103$ である（2 章参照). これらの值と対数正規分布の性質により, $\sigma(\log g)=\sqrt{\ln \left(1+\eta_{g}{ }^{2}\right)} / \ln 10=0.044, \quad \sigma(\log l)=$ $\sqrt{\ln \left(1+\eta_{l}^{2}\right)} / \ln 10=0.108$ となる。 また $x_{i}$ は， $x_{i}=$ $\log \left[\Delta \sigma \sqrt{\pi a_{i} \sec \left(\pi a_{i} / W\right)}\right]$ より計算される.ここで, $a_{i}=a_{1}+\delta(i-0.5), a_{1}=9 \mathrm{~mm}, W=70 \mathrm{~mm}, \Delta \sigma=59.4$ $\mathrm{MPa}$ である. 総和は $i=1$ から $n$ までであり， $n$ は $a=9 \mathrm{~mm}$ から $a=23 \mathrm{~mm}$ の間にふくまれる長さ $\delta$ の 区間数であるから， $n=35$ となる．以上の值を式(38), 
(39)代入すると, $\sigma\left(\log C_{s}\right)=0.239, \sigma\left(m_{s}\right)=0.197$ が 得られる. 一方, 実験值はそれぞれ $0.395,0.331 て ゙$ めるから，理論值と実験值はオーダ的に一致している.

\section{4 考察}

本論文で行った複合変動モデルの検討結果と前報で7 行った試験片内変動モデル（Cの変動として試験片内 での空間的変動のみを考皃たモデル）の検討結果を比 較してみる、まず, き裂伝ば寿命の変動係数 $\eta_{N}$ の理 論値と実験值との一致の程度をみると, Fig. 3 のよう になる，実線が複合変動モデル，破線が試験片内変動 モデルの場合である．複合変動モデルの方が実験とよ りよく一致している.

つぎにき裂伝ぱ寿命の平均值 $\mu_{N}$ に関して両モデル を比較すると, Fig.4 のよらになる. 実線が複合変動 モデル, 破線が試験片内変動モデルの場合である：こ の四から， $\mu_{N}$ の理論值と実験值が一致するように推定 した相関距離 $\delta$ の值は, 複合変動モデルの場合の方が 小さくなることがわかる.これは前報の予想通りであ る. ただし両モデルの $\delta$ の相違は 2 倍程度であり, 複 合変動モデルの $\delta$ は 2 章で述べたように $400 \mu \mathrm{m}$ 程度, 試験片間変動モデルの $\delta$ は前報で述べたように $800 \mu \mathrm{m}$ 程度と推定される.このように, 複合変動モデルにお いても相関距離 $\delta$ は結晶粒径（著者らの実験の供試材 の結晶粒径は数+ $\mu \mathrm{m}$ のオーダである) より1けた大 きい. 相関距離と材料組織の関係は, 今後の興味深い 課題である.

つぎに, $d a / d N=C_{s}(\Delta K)^{m} s$ の形の式を試験片ごと にあてはめたとさ実験的に観察される $C_{s}$ と $m_{s}$ の試 験片間でのばらつきの特性については, この特性が試 験片内変動モデルによって説明されることを前報で示 したが，本論文ではこれが複合変動モデルによっても 同程度侻明されることがわかった。

以上を総合すると， $\eta_{N}$ の実験值との一致度がよい 分だけ複合変動モデルの方が試験片内变動モデルより も実験との一致がよいように思われるが，明確な結論 を得るためには, 実験データをもっと蓄積し, 多くの データにもとづいて両モデルを比較検討する必要があ ると考党られる.

なお, 前報における試験片内変動モデルの検討では, $\eta_{N}$ に関し(理論值/実験値) の平均が 1 となるよう に $\eta_{l} \sqrt{\delta / a_{1}}$ を決めたが，本報では複合変動モデルの 場合之一貫させるために, (理論值一実験值) ${ }^{2}$ の和が 最小となるように $\eta_{l} \sqrt{\delta / a_{1}}$ の值を決め直した. その 結果, 試験片内変動モデルに対し $\eta_{l} \sqrt{\delta / a_{1}}=0.0802$, $\mu_{N}=79800 \sqrt{1+(58.0 / \delta)}$ となった（前報では $\eta_{l}$ $\left.\sqrt{\delta / a_{1}}=0.0943, \mu_{N}=79800 \sqrt{1+(80.0 / \delta)}\right)$. このた め, Fig. 3 と Fig. 4 の破線は前報の曲線上り 低目になっているが，その差は小さく，前報の結論に
影響を及ぼすことはない。

\section{5 結}

論

疲労き裂伝ぱ速度 $d a / d N$ の確率特性に対する複合 変動モデル $\left(d a / d N=C(\Delta K)^{m}\right.$ に和けるC が試験片内 で空間的に変動すると同時に試験片間でも変動すると 考えるモデル) について数学的解析を行い, 解析結果 を著者らの実験と比較した。これより次の結論が得ら れた。

（1）複合変動モデルにもとづいて，き裂がある長さ $a_{1}$ からある長さ $a_{2}$ まで成長するのに要する繰返し数 $N$ の平均値 $\mu_{N}$ と変動係数 $\eta_{N}$ の簡潔な理論式を導い た.

(2) これらの理論式は著者らの実験結果と一致する. 特に $\eta_{N}$ にいては, 試験片内変動モデル ( C の変動 として試験片内変動のみを考光たモデル) より実験と の一致がよい.

（3）複合変動モデルによる相関距離の推定值は, 試 験片内変動モデルによる推定值の $1 / 2$ 程度であり, オ 一ダ的には同じである.

(4) $d a / d N=C_{s}(\Delta K)^{m} s$ の形の式を試験片 ごとにあ てはめたとき実験的に観察される $C_{s}$ と $m_{s}$ のばらつ きは, 試験片内変動モデルによるのと同様に, 複合変 動モデルによってもほぼ説明される。

以上を総合すると, 複合変動モデルの方が試験片内 変動モデルより実験との一致が若干よい上うに思われ るが，明確な結論を得るためには実験的検討をさらに 積み重㸚る必要がある.

終りに, 本研究に対しご助言を賜わった本学田中栄 学長に感謝致します。 また本研究は文部省科学研究費 補助金（一般研究 C) によって行われたことを記し, 謝意を表します。

\section{参 考 文 献}

1) 酒井達雄, 田中道七, 材料, 28, 92 (1979).

2) S. Tanaka, M. Ichikawa and S. Akita, Int. J. Fracture, 17, R121 (1981).

3）市川昌弘, 浜口光夫, 中村武夫, 材料, 33, 8 (1984).

4）木村雄二, 国尾 武, 材料, 32, 1144 (1983).

5) Y.K. Lin and J. N. Yang, Eng. Fract. Mech., 18, 243 (1983).

6) 石川 浩, 鶴井 明, 日本機械学会論文集, A-50, 1309 (1984).

7) 市川昌弘, 中村武夫, 材料, 34, 321 (1985).

8）市川昌弘，秋田 敏，材料， 35, 1177 (1986).

9) S. Akita and M. Ichikawa, to be published in Int. J. Fracture, 32 (1986).

10）田中 栄, 秋田敏, 日本材料強度学会誌, 8, 94 (1973). 